\title{
Changes in nutrient intake during the menstrual cycle of overweight women with premenstrual syndrome
}

\author{
Giordana B. Cross*, John Marley, Helen Miles and Kristyn Willson \\ Department of General Practice, University of Adelaide, Adelaide, South Australia, Australia 5000 \\ (Received 8 December 1999 - Revised 17 October 2000 - Accepted 27 October 2000)
}

\begin{abstract}
This study presents the nutrient data collected from women who were being screened for premenstrual syndrome (PMS) for entry into an intervention study. Screening was by the Steiner self-rated questionnaire. One hundred and forty-four overweight women completed the screening process and eighty-eight met the criteria for PMS. All women kept $4 \mathrm{~d}$ diet diaries pre- and postmenstrually over two menstrual cycles. The mean energy and macronutrient intakes were compared between the pre- and postmenstrual phases. Energy and macronutrient intake was also calculated according to food categories. Goldberg's cut-off limit for the ratio of energy intake to estimated basal metabolic rate was used to exclude data that was incompatible with predicted energy requirements. The diet diaries were also used to determine the mean number of meals or snacks eaten pre- and postmenstrually. Nutrient analysis of the diet diaries of the women with PMS showed a significant increase $(P<0.001)$ in total energy and all macronutrients premenstrually when compared to nutrient intake postmenstrually. Women who did not meet the criteria for PMS showed a significant increase in energy and fat intake $(P<0.05)$ but not in the other macronutrients. When adjusted for energy, data collected from women with PMS showed a premenstrual significant increase in fat, carbohydrate $(P<0.05)$ and simple sugars $(P<0.001)$. There was a significant decrease $(P<0.001)$ in protein premenstrually. Women not meeting the PMS criteria showed no significant difference between pre- and postmenstrual intakes when adjusted for energy. Analysis according to food categories in women with PMS showed a significantly greater intake premenstrually of energy and all macronutrients for cereals, cakes and desserts and high-sugar foods $(P<0 \cdot 001)$. In women with PMS there was a significantly greater number of 'episodes of eating' premenstrually $(P<0 \cdot 001)$. This study provides further evidence, to support the very limited number of earlier studies, that there is a group of women with PMS who increase their nutrient intake during the premenstrual phase. This could potentially be a contributing factor for some women experiencing difficulties adhering to suggested dietary modification and should be considered when counselling premenopausal women.
\end{abstract}

\section{Premenstrual syndrome: Overweight women: Macronutrient and energy intake}

Premenstrual syndrome (PMS) is a group of symptoms of varying degrees of severity, which occurs during the late luteal phase of the menstrual cycle. It is characterised by somatic, appetitive and behavioural changes. These symptoms occur in the week prior to menstruation and cease to be present within a few days of the onset of menses (American Psychiatric Association, 1994). Women have also been reported to have more accidents, suicide attempts and psychiatric admissions premenstrually (Dalton, 1960; Reid, 1986).

Energy and macronutrient intake over the menstrual cycle has been investigated in women with and without premenstrual syndrome. Studies in women without PMS are inconsistent in their findings. They have reported increases of one or more macronutrients as well as total energy intake during the luteal phase of the menstrual cycle (Dalvit-McPhillips, 1983; Manocha et al. 1986; Lissner et al. 1988; Gong et al. 1989; Martini et al. 1994; Barr et al. 1995). In a recent review by Dye \& Blundell (1997) of thirty studies in thirty-seven groups of women, most of these studies (twenty-five) found energy intake to be increased during the premenstrual phase. The remaining studies detected no significant change and two studies reported a greater energy intake during the postmenstrual

\footnotetext{
Abbreviation: PMS, premenstrual syndrome.

* Corresponding author: Giordana B. Cross, fax +61 088204 7778, email crossg@mail.wch.sa.gov.au
} 
phase in women without premenstrual symptoms. This variability in findings may be attributed to the differences in methodology used in obtaining food intake data as well as the selection of the study groups.

The findings with regard to specific changes in macronutrient intakes in women without premenstrual symptoms have been less consistent. Premenstrual increases in one or more macronutrients have been reported. For example, increases in carbohydrate (DalvitMcPhillips 1983; Johnson et al. 1995; Martini 1994) and fat (Tarasuk \& Beaton, 1991) have been found premenstrually.

Studies investigating appetite and macronutrient and energy intake in women with PMS are few in the reported literature. Both-Orthman et al. (1988), using a daily questionnaire to measure appetite and mood over a period of 2 to 9 months, showed a significant increase in appetite in both women with PMS and controls. However, the effect was greater in women with PMS and this correlated with self-rating of mood.

Wurtman et al. found a significant increase in carbohydrate intake in women with PMS premenstrually (Wurtman et al. 1989). In this study nineteen women with PMS and nine controls were admitted as inpatients, and their food consumption was monitored for $48 \mathrm{~h}$ both premenstrually and postmenstrually. Both the meals and snacks available to the subjects had either a high or low carbohydrate content.

This paper reports the baseline energy and macronutrient data obtained during the screening of overweight women for PMS as part of a double-blind placebo-controlled study. The study investigated whether enhancing serotonin neurotransmission with dexfenfluramine alleviated PMS symptoms, including reducing carbohydrate intake premenstrually in overweight women. The study presented the opportunity to collect dietary data in women during the screening process and the study in detail. The data presented here includes macronutrient and total energy intake from all women completing the screening process, including those women who did not meet the criteria for entry into the above-mentioned study. This paper adds to the very limited dietary data available in this group of women. It also presents nutrient analysis in terms of food categories, which has not been previously reported in freeliving women with PMS.

\section{Methods \\ Subject selection and study entry criteria}

Women recruited from poster and newspaper advertisements were screened for entry into the dexfenfluramine study. Participation was voluntary and no financial incentive was given. This study was approved by the Committee on the Ethics of Human Experimentation at the University of Adelaide.

Three hundred and thirteen women who met the initial criteria for entry into the screening process were screened over two menstrual cycles. One hundred and forty-four of these women completed the screening process. Eighty-eight women met the criteria for PMS and fifty-six did not.

All volunteers were required to have regular menstrual cycles, not be taking an oral contraceptive and have a BMI $24-37 \mathrm{~kg} / \mathrm{m}^{2}$ (to comply with the product licence of dexfenfluramine), be of a stable weight and not be on any type of special diet. They were excluded from entry into the screening process if there was a history of psychiatric problems, a history of eating disorders, suffered from medical conditions, including diabetes, renal or hepatic diseases, or were taking medication that could interact with the drug used in the study.

As part of the screening process all women completed the Steiner self-rated PMS questionnaire (Steiner et al. 1980). Women were identified as experiencing PMS when the difference between the pre- and postmenstrual scores for the Steiner self-rated PMS scale was greater than 10 . Women also completed the Nottingham Health Profile (Hunt et al. 1981) and completed diet diaries for $4 \mathrm{~d}$ during both the premenstrual and postmenstrual phases in each cycle.

\section{Nutritional data}

All women with and without PMS kept diet diaries across two menstrual cycles. Initial diaries were commenced postmenstrually on day 5 after menstruation began. Some women also completed diaries for an additional cycle. Diet diaries were recommenced $4 \mathrm{~d}$ prior to the predicted onset of menses and on day 5 after the onset of menses for $4 \mathrm{~d}$ over one menstrual cycle. If menses did not occur on the predicted day, subjects were instructed to continue recording their food intake until it occurred. In these cases, the food intake for $4 \mathrm{~d}$ prior to menses was analysed. In cases where menses occurred early, subjects continued with the screening process for another cycle (sixteen women completed a third cycle). The mean energy and macronutrients were calculated for the premenstrual (late luteal) and postmenstrual (follicular) phases. As an indication of the reliability and level of possible under reporting the recorded energy intake-BMR was calculated. Cases were excluded based on Goldberg's et al. (1991) cut-off limits for this ratio (1.06 for records of $4 \mathrm{~d}$ ). This resulted in six women meeting the PMS criteria being excluded and sixteen from the group not meeting the criteria. Consistency over the two cycles was checked using statistical methods ( $t$ test).

Previous studies showed that keeping dietary records for 4 d (Basiotis, 1987; Potoska et al. 1990) was the appropriate time. The timing of when the diet diaries were kept was based on studies from the literature, which showed that premenstrual symptoms worsened several days prior to the onset of menstruation and had ceased by day 5 from the commencement of menstruation. At the first visit prior to the commencement of screening, weight, height and hip-waist ratios were measured in all women.

All subjects were interviewed and instructed on how and when to fill out the diet diaries. They were requested to continue with their usual diet. Detailed instructions on recording the quantities eaten were given including the use of household metric measures. When composite dishes were eaten, participants were requested to record the recipes used. If eating out, subjects were asked to identify the type of place the food was purchased from and 
Table 1. Description of food categories used in nutrient analysis

\begin{tabular}{ll}
\hline Food category & \multicolumn{1}{c}{ Foods included } \\
\hline Cereal products & Breakfast cereals, bread, pasta, rice, dry biscuits \\
Cakes and desserts & Cakes, buns, sweet biscuits, ice cream, \\
& Custard, commercial desserts, Sweet yoghurt \\
& (sweetened with sugar or artificial sweetener) \\
Dailk, cheese, unsweetened yoghurt & Oil, margarine, butter, cream \\
Fats & All meats including processed meats, sausages, \\
Composite foods & chicken, turkey, fish and other mixed meat and \\
& vegetable dishes, Vegemite and savoury spreads \\
Vegetables & All vegetables, fresh, dried and frozen \\
Fruit & All fresh, tinned, frozen and dried fruit \\
High-sugar foods & Confectionery, jams, honey, sugar added to cereal and \\
& drinks, sweet drink additives, non-dairy iceblocks \\
Snack foods & Potato crisps, corn chips, extruded snacks, nuts \\
Beverages & Soft drinks, cordials, fruit juices, fruit juice drinks, \\
& flavoured milks, hot chocolate and related drinks, alcoholic \\
& beverages
\end{tabular}

instructed on how to describe the foods and quantities eaten. Diaries were requested to be returned as soon as possible after their completion. Upon return of the diaries, they were checked through and clarified over the phone with the individual subject. Nutritional analyses of the diaries were performed using Diet3 version 4.22 (Xyris Software Pty Ltd, Highgate Hill, Queensland, Australia), with additions to the database obtained from food companies where appropriate. Where quantities were not specified standard portion sizes were used. For each subject, the mean energy and macronutrient intake over the $4 \mathrm{~d}$ was calculated for the premenstrual and postmenstrual phases.

The diet diaries were also used to record the number of episodes of eating a meal or a snack over each $4 \mathrm{~d}$ interval. 'Episodes of eating' was used due to the differences in the dietary habits in the women and the difficulty in separating snacks from main meals for some women. This enabled a comparison to be made between the two periods, of the number of episodes when food was eaten.

For women with PMS, the nutrient data were also analysed according to food categories. The foods were categorised into groups based, with some modification, on the Australian National Nutrition Survey held in 1995 and Magarey \& Boulton (1995). Foods were grouped under the food categories shown in Table 1.

The mean $\mathrm{kJ}$ and macronutrients were analysed for each group using the original data. The nutrient data for each food category were also calculated in terms of the percent of total kilojoules, protein, fat, carbohydrate, simple sugars and complex carbohydrates.

\section{Statistical analysis}

Statistical analyses were performed using Stata 5.0 (Stata Corporation, 702 University Drive East, College Station, TX, 77840 USA). Paired $t$ tests (for normally distributed data) and Wilcoxon sign rank test (non-normal data) were used to compare whether there was a significant difference in energy and macronutrient intake between the premenstrual and postmenstrual phases. Macronutrient intake was also calculated as percent of energy. Spearman's correlation coefficient was used to identify whether there was a relationship between the severity of PMS symptoms as measured by the Steiner self-rated scores (using total scores) and changes in nutrient and total energy intake.

\section{Results}

The eighty-two women identified with PMS had a mean age of 37.2 (SD 5.2) years and a mean BMI of 29 (SD 3.6) $\mathrm{kg} / \mathrm{m}^{2}$. The mean length of the menstrual cycle was $28 \mathrm{~d}$ with a range of 23-38 d. The forty women without PMS had a mean age of 37.2 (SD 6.9) years, a mean BMI of 29.2 (SD $3 \cdot 1) \mathrm{kg} / \mathrm{m}^{2}$. The mean length of the menstrual cycle was $27 \mathrm{~d}$ with a range of $23-36 \mathrm{~d}$. There were no great differences between women with and without PMS with regard to age, BMI and length of menstrual cycle.

For women with PMS, the premenstrual median score of the Steiner self-rated questionnaire was 25.5 (range 13.734) compared to a median postmenstrual score of 2 (range 0-14.6). In the women who did not meet the criteria for entry into the study, the premenstrual median score of the Steiner self-rated questionnaire was 23 (range 8-34) compared to a median postmenstrual score of 4 (range 029).

Table 2 presents the baseline nutritional data for the women who completed the screening process. For the group of women who were identified to be suffering from PMS, there was a statistically significant $(P<0.001)$ greater nutrient intake premenstrually compared with the postmenstrual intake for each nutrient, as well as total intake. In comparison, for women without PMS there were no significant differences between the premenstrual and postmenstrual phases for all nutrients except fat and total energy $(P<0 \cdot 05)$.

In the eighty-two women with PMS, adjustment of macronutrient intake as a percentage of total energy intake showed significant increases in the percentage of carbohydrate fat $(P<0.05)$, and simple sugar $(P<0.001)$. There was a significant decrease in the percent of protein $(P<$ $0.001)$ in the premenstrual phase as compared with this group's postmenstrual data (Table 3). For complex carbohydrate there was also a decrease premenstrually but this was not significant $(P 0 \cdot 07)$. In the forty women 
Table 2. The mean (over 4 d) pre- and postmenstrual energy, macronutrient intake and percentage change for each nutrient for women with and without PMS

(Values are means and their standard deviations)

\begin{tabular}{|c|c|c|c|c|c|c|c|c|c|c|c|c|}
\hline & Carbohydrate & & Complex & & Simple sugars & & Protein & & Fat & & Energy & \\
\hline & (g) & SD & carbohydrate (g) & SD & (g) & SD & (g) & SD & (g) & SD & (g) & SD \\
\hline \multicolumn{13}{|l|}{ Women with PMS ( $n$ 82) } \\
\hline Premenstrual & 245 & $50 \cdot 1$ & 131 & 31 & 113 & 40.5 & 78.7 & $17 \cdot 6$ & $81 \cdot 6$ & 23.5 & 8648 & 1727 \\
\hline Postmenstrual & 167 & $36 \cdot 3$ & 95.9 & 23.5 & 71 & 23.5 & $65 \cdot 6$ & 16 & $53 \cdot 6$ & 15 & 6048 & 1268 \\
\hline Percentage change* & $32 \dagger$ & & $26 \cdot 8 \dagger$ & & $37.2 \dagger$ & & $16 \cdot 6 \dagger$ & & $34 \dagger$ & & $30 \dagger$ & \\
\hline \multicolumn{13}{|c|}{ Women without PMS ( $n$ 40) } \\
\hline Premenstrual & 220 & 50 & 118 & $29 \cdot 7$ & 101 & 35 & 74.5 & $15 \cdot 3$ & $74 \cdot 2$ & 21 & 7895 & 1347 \\
\hline Postmenstrual & 211 & 53 & 116 & 32 & 94.5 & 32 & 71.5 & 17 & 67 & 21 & 7433 & 1697 \\
\hline Percentage change & $4 \cdot 1$ & & 0.9 & & $6 \cdot 4$ & & $4 \cdot 0$ & & $9 \cdot 7 \ddagger$ & & $5.8 \ddagger$ & \\
\hline
\end{tabular}

PMS, premenstrual syndrome.

* Percentage change between premenstrual and postmenstrual nutrient analysis.

$\dagger P<0.001$ (paired $t$ test)

$\ddagger P<0.05$.

without PMS, adjustment for energy showed no significant difference between premenstrual and postmenstrual macronutrient intakes.

Tables 4-6 display the mean energy and macronutrient intake analysed, according to food categories, for women with PMS. The kilojoules (Table 4) from all food categories except for the fruit, vegetable and milk categories were significantly greater $(P<0.001)$ premenstrually compared to postmenstrually. The absolute protein, fat, carbohydrate and complex carbohydrate was significantly higher premenstrually than postmenstrually for the cereal, cakes and desserts and the high sugar foods categories $(P<0.001$; Tables 5 and 6$)$. Composite savoury dishes $(P<0.001)$, drinks $(P<0.001)$ and savoury snacks $(P<0 \cdot 05)$ contributed more carbohydrate premenstrually (Table 6).

Analysis of the data as the percentage of the total energy and macronutrients that each food category provided is also shown in Tables 4-6. The food categories 'cakes and desserts' and 'high-sugar foods' contributed a higher percentage for all macronutrients and energy premenstrually. When grouped together, these two food categories provided $26.38 \%$ of the total kilojoules premenstrually compared with $15.9 \%$ postmenstrually. They also contributed $27.6 \%$ of the total fat premenstrually, $31.6 \%$ of the total carbohydrate, $15.8 \%$ of the total complex carbohydrate and $49.6 \%$ total simple sugars compared to $15.8 \%$ total fat, $20.8 \%$ total carbohydrate, $10.1 \%$ of the total complex carbohydrate and $35.2 \%$ simple sugars, postmenstrually. The remaining food groups either contributed a greater percentage postmenstrually or showed no great difference between the two phases.

For women with PMS symptoms the mean number of times per day they consumed food was 5.5 (SD 1.2) premenstrually compared to 4.2 (SD 0.98 ) postmenstrually. Paired $t$ test showed a significant difference $(P<0 \cdot 001)$. There was no difference for women without PMS.

Spearman's correlation coefficient was used to identify whether there was a relationship between the severity of PMS symptoms, as measured by the Steiner self-rated PMS scale and the change observed in the unadjusted nutrient intake. When Spearman's correlation coefficient was calculated for all subjects (those with and without PMS), there was a weak correlation (Spearman's $\rho$ 0.34, $P<$ 0.001, 120 degrees of freedom; d.f.) for carbohydrate. For complex carbohydrate Spearman $\rho 0.29, P<0.05$ and simple sugars Spearman's $\rho 0, P<0 \cdot 05$. There was also a weak correlation between the change in fat intake and total energy intake with regard to change in PMS score. This was $0.27(P<0.05)$ and $0.32(P<0.05)$ respectively. The correlation for protein was very weak (Spearman's $\rho 0 \cdot 19$, $P<0.05)$. For women with PMS, Spearman's correlation

Table 3. Macronutrient intake for eighty-two women with PMS expressed as percent of total energy intake and for forty women without PMS (Values are means and their standard deriations)

\begin{tabular}{|c|c|c|c|c|c|}
\hline Macronutrient & Premenstrual $\%$ of energy & SD & Postmenstrual $\%$ of energy & SD & Significance \\
\hline \multicolumn{6}{|l|}{ Women with PMS } \\
\hline Carbohydrate & $45 \cdot 58$ & $5 \cdot 0$ & 44.57 & & $P<0.05$ \\
\hline Fat & 34.6 & 4.8 & 32.61 & 4.6 & $P<0.05$ \\
\hline Protein & $15 \cdot 66$ & 2.9 & 18.54 & $3 \cdot 2$ & $P<0.001$ \\
\hline Simple sugars & 20.94 & $5 \cdot 8$ & 18.94 & $5 \cdot 2$ & $P<0.001$ \\
\hline Complex carbohydrates & 24.64 & $5 \cdot 1$ & $25 \cdot 58$ & $4 \cdot 7$ & $P=0.067$ \\
\hline \multicolumn{6}{|l|}{ Women without PMS } \\
\hline Carbohydrate & 44.32 & $7 \cdot 1$ & 45.34 & 6.5 & $P=0.34$ \\
\hline Fat & 35.0 & $6 \cdot 6$ & 33.24 & 5.4 & $P=0.13$ \\
\hline Protein & 16.09 & 2.6 & 16.59 & 2.8 & $P=0.28$ \\
\hline Simple sugars & $20 \cdot 1$ & 4.8 & $20 \cdot 04$ & $6 \cdot 6$ & $P=0.93$ \\
\hline Complex carbohydrates & 23.98 & $6 \cdot 1$ & $25 \cdot 23$ & 5.5 & $P=0.08$ \\
\hline
\end{tabular}

PMS, premenstrual syndrome. 
Table 4. The mean energy and percentage intake for each food category for premenstrual and postmenstrual phases for eighty-two women with PMS

\begin{tabular}{|c|c|c|c|c|}
\hline Food type & Premenstrual (kJ) & Total nutrients (\%) & Postmenstrual (kJ) & Total nutrients (\%) \\
\hline Cereal & $1745^{\star} \ddagger$ & $20 \cdot 62 † \ddagger$ & 1393 & $23 \cdot 3$ \\
\hline Milk & 701 & $8.3^{*} \ddagger$ & 656 & $10 \cdot 89$ \\
\hline Composite savoury dishes & $1797^{\star} \ddagger$ & $20 \cdot 8 † \ddagger$ & 1454 & $24 \cdot 1$ \\
\hline Vegetables & 482 & $5 \cdot 62^{\star} \ddagger$ & 432 & $7 \cdot 19$ \\
\hline Fruit & 213 & $2.58^{*} \S$ & 227 & 4.02 \\
\hline Fat & $376+\S$ & $4 \cdot 27$ & 276 & 4.5 \\
\hline Cake and desserts & $1327^{\star} \ddagger$ & $15 \cdot 02^{*} \ddagger$ & 648 & $10 \cdot 46$ \\
\hline High-sugar foods & $995^{\star} \S$ & $11 \cdot 24^{\star} \S$ & 332 & 5.47 \\
\hline Drinks & $588^{*} \ddagger$ & $6 \cdot 67$ & 420 & $6 \cdot 76$ \\
\hline Savoury snacks & $316+\S$ & 3.6 & 175 & $2 \cdot 71$ \\
\hline
\end{tabular}

PMS, premenstrual syndrome.

* $P<0.001$.

$\dagger P<0.05$.

$\ddagger$ Paired $t$ test.

$\S$ Wilcoxon sign rank test.

coefficient was weak (Spearman's $\rho 0.26, P<0 \cdot 05,80$ d.f.) for carbohydrate. There was also a weak correlation between the change in fat intake and total energy intake with regard to change in PMS score. This was $0.27(P<$ $0.05)$ and $0.29 \quad(P<0.05)$ respectively. Spearman's correlation coefficient for protein, simple sugars and complex carbohydrates were not significant. In women without PMS there were no great correlations between the Steiner self-rated PMS scale and energy and macronutrient intake.

\section{Discussion}

This study presents the energy and nutrient intake data, which has not been previously reported, of overweight women with PMS. The data presented here support the very small number of reports found in the literature in women of normal weight with PMS, where there are increases in both energy and carbohydrate intakes during the premenstrual phase (Wurtman et al. 1989). This study also showed a significant increase $(\mathrm{g})$ in both protein and fat. Adjustment for energy also showed a significant increase in total carbohydrate, as well as significant premenstrual increase in simple sugars and premenstrual decrease in complex carbohydrate. After adjustment for energy there was also an increase in fat premenstrually and a decrease in protein. Analysis of the data according to food categories helps to clarify these findings. For all the food categories except for 'milk', 'vegetables' and 'fruit', there was a significantly greater kJ intake premenstrually $(P<0 \cdot 001)$. However

Table 5. The mean protein and fat and the percentage of the total protein and fat intake for each food category for premenstrual and postmenstrual phases of eighty-eight women with PMS

(Values are means and percentage intake)

\begin{tabular}{|c|c|c|c|c|}
\hline Food type & Premenstrual (g) & Total nutrients (\%) & Postmenstrual (g) & Total nutrients (\%) \\
\hline \multicolumn{5}{|l|}{ Protein } \\
\hline Cereal & $14 \cdot 1^{\star} \ddagger$ & 18.5 & 11.52 & $18 \cdot 17$ \\
\hline Milk & $12 \cdot 02$ & $15 \cdot 2$ & $10 \cdot 9$ & $16 \cdot 49$ \\
\hline Composite savoury dishes & $32 \cdot 88 † \ddagger$ & $40.84 † \ddagger$ & 29.6 & $44 \cdot 2$ \\
\hline Vegetables & 4.35 & 5.54 & 4.02 & $6 \cdot 2$ \\
\hline Fruit & 0.79 & 1.08 & 0.78 & 1.32 \\
\hline Fat & 0.16 & 0.2 & 0.11 & 0.18 \\
\hline Cake and desserts & $6 \cdot 3^{*} \ddagger$ & $8 \cdot 12^{\star} \ddagger$ & 3.53 & $5 \cdot 41$ \\
\hline High-sugar foods & $2.99^{\star} \S$ & $4.03^{*} \S$ & 0.88 & 1.39 \\
\hline Drinks & $2 \cdot 69$ & $3 \cdot 38+\S$ & $2 \cdot 5$ & 3.9 \\
\hline Savoury snacks & $1.83+\S$ & $2 \cdot 3$ & 1.07 & 1.6 \\
\hline \multicolumn{5}{|l|}{ Fat } \\
\hline Cereal & $5 \cdot 29^{*} \ddagger$ & $6 \cdot 8$ & $3 \cdot 82$ & $7 \cdot 3$ \\
\hline Milk & 9.35 & $12 \cdot 37+\S$ & 8.5 & $16 \cdot 31$ \\
\hline Composite savoury dishes & $22 \cdot 3^{*} \ddagger$ & $27 \cdot 6^{\star} \ddagger$ & $17 \cdot 9$ & $34 \cdot 01$ \\
\hline Vegetables & 3.63 & $4 \cdot 28+\S$ & 3.39 & $6 \cdot 15$ \\
\hline Fruit & 0 & 0 & 0.03 & 0.1 \\
\hline Fat & $10.03+\S$ & $12 \cdot 07$ & $7 \cdot 25$ & $13 \cdot 47$ \\
\hline Cake and desserts & $14 \cdot 7^{\star} \ddagger$ & $16 \cdot 4^{\star} \ddagger$ & $6 \cdot 23$ & 11.6 \\
\hline High-sugar foods & $9 \cdot 6 * \S$ & $11 \cdot 2^{*} \S$ & 2.31 & $4 \cdot 2$ \\
\hline Drinks & 0.58 & 0.78 & 0.46 & 0.85 \\
\hline Savoury snacks & $5 \cdot 23+\S$ & $6 \cdot 26$ & 3.1 & 5.02 \\
\hline
\end{tabular}

PMS, premenstrual syndrome.

* $P<0.001$.

$\dagger P<0.05$.

$\ddagger$ Paired $t$ test.

$\S$ Wilcoxon sign rank test. 
Table 6. The mean carbohydrate, complex carbohydrate and simple sugars and the percentage of the total intake for each food category for premenstrual and postmenstrual phases for eighty-two women with PMS

(Values are means and percentages)

\begin{tabular}{|c|c|c|c|c|}
\hline Food type & Premenstrual (g) & Total nutrients (\%) & Postmenstrual (g) & Total nutrients (\%) \\
\hline \multicolumn{5}{|l|}{ Carbohydrate } \\
\hline Cereal & $78 \cdot 0^{*} \ddagger$ & $32 \cdot 26^{\star} \ddagger$ & $62 \cdot 15$ & $37 \cdot 2$ \\
\hline Milk & 9.82 & $4.04^{\star} \S$ & 9.81 & $5 \cdot 74$ \\
\hline Composite savoury dishes & $24 \cdot 14^{*} \ddagger$ & 9.99 & $16 \cdot 88$ & $10 \cdot 24$ \\
\hline Vegetables & $15 \cdot 54$ & $6 \cdot 49^{\star} \S$ & 13.66 & $8 \cdot 29$ \\
\hline Fruit & 11.83 & $4.9^{*} \S$ & 12.7 & 7.89 \\
\hline Fat & 0.23 & $0.09^{\circ}$ & 0.22 & 0.12 \\
\hline Cake and desserts & $43 \cdot 19^{\star} \ddagger$ & $17 \cdot 24^{\star} \ddagger$ & 21.61 & $12 \cdot 4$ \\
\hline High-sugar foods & $36 \cdot 33^{\star} \S$ & $14 \cdot 37^{\star} \S$ & $14 \cdot 28$ & 8.39 \\
\hline Drinks & $18 \cdot 85^{\star} \S$ & 7.6 & 11.88 & 7.07 \\
\hline Savoury snacks & $5 \cdot 76+\S$ & $2 \cdot 49$ & 2.66 & 1.64 \\
\hline \multicolumn{5}{|l|}{ Simple sugars } \\
\hline Cereal & $6 \cdot 42+\S$ & $5.99+\S$ & 4.9 & $6 \cdot 9$ \\
\hline Milk & 9.55 & $8 \cdot 9^{\star} \S$ & $9 \cdot 61$ & $13 \cdot 4$ \\
\hline Composite savoury dishes & 4.55 & $4 \cdot 25^{3}$ & 3.21 & 4.92 \\
\hline Vegetables & 3.69 & $3 \cdot 6^{\star} \S$ & 3.64 & 5.46 \\
\hline Fruit & 10.69 & $10 \cdot 35^{\star} \ddagger$ & 11.62 & $17 \cdot 17$ \\
\hline Fat & 0.22 & 0.19 & 0.15 & 0.2 \\
\hline Cake and desserts & $24.78^{*} \S$ & $22 \cdot 01 \dagger \ddagger$ & 12.52 & $17 \cdot 16$ \\
\hline High-sugar foods & $35.98 * \S$ & $27.63^{\star} \S$ & 13.35 & $18 \cdot 15$ \\
\hline Drinks & $18.06^{\star} \S$ & $15 \cdot 3$ & 11.36 & $15 \cdot 14$ \\
\hline Savoury snacks & 0.49 & 0.52 & 0.37 & 0.51 \\
\hline \multicolumn{5}{|l|}{ Complex carbohydrates } \\
\hline Cereal & $71 \cdot 86^{\star} \ddagger$ & 54.13†‡ & $57 \cdot 32$ & 59.42 \\
\hline Milk & 0.27 & 0.2 & 0.20 & 0.20 \\
\hline Composite savoury dishes & $19 \cdot 47^{\star} \ddagger$ & 14.61 & 14.06 & 15 \\
\hline Vegetables & $11 \cdot 77 \dagger \ddagger$ & 9.56 & $9 \cdot 6$ & $10 \cdot 5$ \\
\hline Fruit & 0.99 & 0.81 & 0.89 & 1.06 \\
\hline Fat & 0.01 & 0.01 & 0.003 & 0.003 \\
\hline Cake and desserts & $18.51^{\star} \ddagger$ & $13 \cdot 87^{\star} \ddagger$ & $9 \cdot 17$ & $9 \cdot 3$ \\
\hline High-sugar foods & $2 \cdot 25^{\star} \S$ & $2 \cdot 0 \star \S$ & 0.81 & 0.83 \\
\hline Drinks & $0.77+\S$ & 0.6 & 0.50 & 0.54 \\
\hline Savoury snacks & $5 \cdot 31+\S$ & 3.99 & $2 \cdot 3$ & 2.43 \\
\hline
\end{tabular}

PMS, premenstrual syndrome.

* $P<0.001$.

$+P<0.05$

$\ddagger$ Paired $t$ test.

$\S$ Wilcoxon sign rank test.

when analysed in terms of the percentage that each group contributed to the total kilojoule intake, the 'cake and dessert' and 'high-sugar foods' contributed a higher percentage premenstrually, while the other groups either contributed more postmenstrually or there was little difference between the two phases. This was reflected in the analysis of the macronutrients, where there was a greater percentage contribution premenstrually from these two groups. These findings show that there is a preference for sweet high-carbohydrate, high-fat foods in this group of women. They support other findings in women with and without PMS.

Previously reported studies in women, both with and without PMS, have shown increases in energy and macronutrient intake during the premenstrual compared to the postmenstrual phase. However, although many studies have shown increased total energy intake, there is a lack of consistency when macronutrients are analysed. Lissner et al. (1988) found in a group of normal weight women without PMS that their mean daily energy intake was $364 \mathrm{~kJ}$ higher during the $10 \mathrm{~d}$ premenstrually compared to $10 \mathrm{~d}$ postmenstrually. Tarasuk \& Beaton (1991) retrospectively demonstrated an increase in energy, fat and fat/
1000 Kcal premenstrually but no difference in protein or carbohydrate in women without PMS.

In the few studies of women with PMS, increases in appetite and food intake, in particular foods high in carbohydrates, have been reported during the late luteal phase (Both-Orthman et al. 1988). Wurtman et al. (1989) monitored the food intake of nineteen women with PMS and nine controls for $48 \mathrm{~h}$ pre- and postmenstrually in an inpatient setting. In women with PMS during the late luteal phase there was a 24 and $43 \%$ increase in carbohydrate intake at main meals and snacks respectively. There was no change in protein intake and fat intake rose in proportion to total energy intake. No change in food intake was seen in the control group. In contrast, our study in free-living women showed significant increases in energy and all macronutrients, including protein, in women with PMS. This difference may be due to our study design. In Wurtman et al.'s (1989) study, main meals and snacks provided were either high in carbohydrate or protein. In this current study subjects were free living with ad libitum food choices. As many foods contain a combination of macronutrients, it is difficult to demonstrate a preference for a specific nutrient. Another reason may be that there is 
not a specific preference for craving for carbohydrate, but rather a desire for pleasant tasting sweet high-fat foods as suggested by Hill \& Heaton-Brown (1994).

One of the main hypotheses for increased food intake in women with PMS is that these women have low brain serotonin levels premenstrually. Carbohydrate consumption can influence brain serotonin levels by increasing the ratio of tryptophan:large amino acids. Tryptophan, the precursor of serotonin, competes with large amino acids for entry into the brain. Both animal and human studies support the hypothesis that low levels of brain serotonin may play a role in PMS, including increasing carbohydrate intake. Measurement of total blood serotonin, which is believed to reflect brain levels, during the last $10 \mathrm{~d}$ of the menstrual cycle, was found to be lower in women with PMS compared to controls (Rapkin et al. 1987). A highcarbohydrate meal in comparison to a high-protein meal results in elevated blood tryptophan, which is a precursor of serotonin and can cross the blood-brain barrier. It has been proposed that the observed increase in carbohydrate is an attempt to elevate brain serotonin levels in order to improve mood. A pilot study in women with PMS given Ltryptophan $(6 \mathrm{~g} / \mathrm{d})$ orally showed a reduction in PMS symptoms (Steinberg et al. 1994).

Craving of foods also occurs in women without PMS and conditions such as obesity, bulimia nervosa and seasonal affective disorder. 'Carbohydrate craving', a term used to describe a preference for carbohydrate-containing foods has also been reported in some obese individuals (Lieberman et al. 1986) and those with seasonal affective disorder (Rosenthal et al. 1989). It has been proposed that carbohydrate craving in obese subjects may be related to reduced brain serotonin levels. This has been supported indirectly by the measurement of 5-hydroxytryptamine, a precursor of serotonin, in platelet-poor plasma (Blum et al. 1993). Obese individuals of both sexes and lean males who craved carbohydrate-containing foods had lower plasma 5hydroxytryptamine compared to lean individuals who were not carbohydrate cravers.

Fernstrom (1994) in a review of dietary amino acids and brain function argues that 'carbohydrate cravers' as a subtype of obese individuals are likely not to exist. These individuals tend to have a preference for high-fat and highcarbohydrate snacks such as chocolate bars. These snacks also have sufficient quantities of protein to prevent a rise in brain tryptophan and therefore serotonin. He suggests that if there were a drive to consume carbohydrate then all carbohydrate foods would be equally craved, which is not the case. Fernstrom theorises that it is the natural human preference for sweet high-fat foods that leads to the choice of these foods.

Other work investigating food cravings in women supports the likelihood that the desire for certain foods is not solely biological, but that psychological factors play an important role. Also, food craving seems to be fairly widespread in the general population. Weingarten \& Elston (1991) retrospectively found that in 758 female and 380 male Canadian college undergraduate students, $97 \%$ of the female and $68 \%$ of the male students reported experiencing food cravings. Chocolate was the most frequently craved food among women and they craved it more frequently than men. In women there also appeared to be more specific triggers (e.g. TV commercials, stress or boredom) compared to men, who most often craved foods as a response to hunger. Hill \& Heaton-Brown (1994) report similar findings in a group of twenty-five healthy women over a 5 -week period. They found that $49 \%$ of the reported cravings were for chocolate or chocolate-containing foods, $16 \%$ for sweet foods and $12 \%$ for savoury foods. Other foods were much less frequently craved. When relating this to the menstrual cycle, they found an increase in the cravings of food premenstrually. However, there was no selective craving of one food over another and it was concluded, given the mixed macronutrient content of these foods, that the subjects were not carbohydrate cravers.

Our data provide evidence that there is a premenstrual increase in energy and nutrient intake in overweight women with PMS symptoms. The preference for 'sweet foods' that are high in carbohydrate, fat and also contain some protein supports the available literature, that this is not specifically 'carbohydrate craving'. It also presents data, not previously documented, on the frequency of food consumption in women with PMS. This premenstrual increase has implications for women who are experiencing PMS symptoms and trying to lose weight. Increased appetite and difficulty in coping with this may decrease successful longer-term changes in dietary behaviour. Recognition that this could be a contributing factor in individual women is an important consideration during dietary counselling.

\section{Acknowledgement}

We would like to thank and acknowledge the important role played in this study by the research nurse Julie O'Brien.

\section{References}

American Psychiatric Association (1994) Diagnostic and Statistical Manual of Mental Disorders, 4th ed. Washington, DC: American Psychiatric Association.

Barr SI, Janelle KC \& Prior JC (1995) Energy intakes are higher during the luteal phase of ovulatory menstrual cycles. American Journal of Clinical Nutrition 61, 39-43.

Basiotis PP (1987) Number of days of food intake records required to estimate individual and group nutrient intakes with defined confidence. Journal of Nutrition 117, 1138-1141.

Blum I, Nessiel L, Graff E, Harsat A, Gabbay U, Sulkes J, Raz O \& Vered Y (1993) Food preferences, body weight, and plateletpoor plasma serotonin and catecholamines. American Journal of Clinical Nutrition 57, 486-489.

Both-Orthman B, Rubinow DR, Hoban MC, Malley J \& Grover GN (1988) Menstrual cycle phase-related changes in appetite in patients with premenstrual syndrome and in control subjects. American Journal of Psychiatry 145, 628-631.

Dalton K (1960) Menstruation and accidents. British Medical Journal 2, 1425.

Dalvit-McPhillips S (1983) The effect of the human menstrual cycle on nutrient intake. Physiology and Behaviour 31, 209212.

Dye L \& Blundell JE (1997) Menstrual cycle and appetite control: implications for weight regulation. Human Reproduction 12, 1142-1151.

Goldberg GR, Black AE, Jebb SA, Cole TJ, Murgatroyd PR, 
Coward WA \& Prentice AM (1991) Critical evaluation of energy intake data using fundamental principals of energy physiology 1. Derivation of cut-off limits to identify underrecording. European Journal of Clinical Nutrition 45, 569-581.

Gong EJ, Garrel D \& Calloway DH (1989) Menstrual cycle and voluntary food intake. American Journal of Clinical Nutrition 49, 252-258.

Hill AJ \& Heaton-Brown L (1994) The experience of food craving: a prospective investigation in healthy women. Journal of Psychosomatic Research 38, 804-814.

Hunt SM, McKenna SP, McEwen J, Williams J \& Papp E (1981) The Nottingham health profile: Subjective health status and medical consultations. Social Science and Medicine 15A, 221229.

Johnson WG, Carr-Nangle RE \& Bergeron KC (1995) Macronutrient intake, eating habits and exercise as moderators of menstrual distress in healthy women. Psychosomatic Medicine 57, 324-330.

Lieberman HR, Wurtman JJ \& Chew B (1986) Changes in mood after carbohydrate consumption among obese individuals. American Journal of Clinical Nutrition 44, 772-778.

Lissner L, Stevens J, Levitsky DA, Rasmussen KM \& Strupp BJ (1988) Variation in energy intake during the menstrual cycle: implications for food-intake research. American Journal of Clinical Nutrition 48, 956-962.

Magarey A \& Boulton J (1995) The Adelaide nutrition study. 3. Food sources at ages 11, 13 and 15 years. Australian Journal of Nutrition and Dietetics 52, 124-130.

Manocha S, Choudhuri G \& Tandon BN (1986) A Study of the dietary intake in pre and post-menstrual period. Human Nutrition: Applied Nutrition 40A, 213-216.

Martini MC, Lampe JW, Slavin JL \& Kurzer MS (1994) Effect of the menstrual cycle on energy and nutrient intake. American Journal of Clinical Nutrition 60, 895-899.

Potoska AL, Block G \& Hartman AM (1990) The apparent validity of diet questionnaires is influenced by number of diet record days used for comparison. Journal of the American Dietetic Association 90, 810-813.

Rapkin AJ, Edelmuth E, Chang LC, Reading AE, McGuire MT \& Su TP (1987) Whole blood serotonin in premenstrual syndrome. Obstetrics and Gynaecology 70, 533-537.

Reid R (1986) Pre menstrual Syndrome; the time for introspection. Medical Journal of Obstetrics and Gynaecology 155, 921.

Rosenthal NE, Genhart MJ, Caballero B, Jacobsen FM, Skwerer RG, Coursey RD, Rogers S \& Spring BJ (1989) Psychobiological effects of carbohydrate and protein rich meals in patients with seasonal affective disorder and normal controls. Biological Psychiatry 25, 1029-1040.

Steinberg S, Lawrence A, Young SN \& Belanger MC (1994) Tryptophan in the treatment of late luteal phase dysphoric disorder: a pilot study. Journal of Psychiatry and Neuroscience 19, 114-119.

Steiner M, Haskett F \& Carroll BJ (1980) Premenstrual tension syndrome: The development of research diagnostic criteria and new rating scales. Acta Psychiatrica Scandinavica 62, 177190.

Tarasuk V \& Beaton GH (1991) Menstrual-cycle patterns in energy and macronutrient intake. American Journal of Clinical Nutrition 53, 442-447.

Weingarten HP \& Elston D (1991) Food cravings in a college population. Appetite 17, 167-175.

Wurtman JJ, Brzezinski A, Wurtman RJ \& Laferrere B (1989) Effect of nutrient intake on premenstrual depression. American Journal of Obstetrics and Gynaecology 161, 1228-1234. 